\title{
Probing tRNA interaction with biogenic polyamines
}

\author{
AMIN AHMED OUAMEUR, PHILIPPE BOURASSA, and HEIDAR-ALI TAJMIR-RIAHI \\ Department of Chemistry-Biology, University of Québec at Trois-Rivières, Trois-Rivières, Québec, G9A 5H7, Canada
}

\begin{abstract}
Biogenic polyamines are found to modulate protein synthesis at different levels. This effect may be explained by the ability of polyamines to bind and influence the secondary structure of tRNA, mRNA, and rRNA. We report the interaction between tRNA and the three biogenic polyamines putrescine, spermidine, spermine, and cobalt(III)hexamine at physiological conditions, using FTIR spectroscopy, capillary electrophoresis, and molecular modeling. The results indicated that tRNA was stabilized at low biogenic polyamine concentration, as a consequence of polyamine interaction with the backbone phosphate group. The main tRNA reactive sites for biogenic polyamine at low concentration were guanine-N7/O6, uracil-O2/O4, adenine- $\mathrm{N} 3$, and 2' OH of the ribose. At high polyamine concentration, the interaction involves guanine- $\mathrm{N} 7 / \mathrm{O} 6$, adenine- $\mathrm{N} 7$, uracil-O2 reactive sites, and the backbone phosphate group. The participation of the polycation primary amino group, in the interaction and the presence of the hydrophobic contact, are also shown. The binding affinity of biogenic polyamine to tRNA molecule was in the order of spermine $>$ spermidine $>$ putrescine with $K_{\text {Spm }}=8.7 \times 10^{5} \mathrm{M}^{-1}, K_{\text {Spd }}=6.1 \times 10^{5} \mathrm{M}^{-1}$, and $K_{\text {Put }}=1.0 \times 10^{5} \mathrm{M}^{-1}$, which correlates with their positively charged amino group content. Hill analysis showed positive cooperativity for the biogenic polyamines and negative cooperativity for cobalt-hexamine. Cobalt(III)hexamine contains high- and low-affinity sites in tRNA with $K_{1}=3.2 \times 10^{5} \mathrm{M}^{-1}$ and $K_{2}=1.7 \times 10^{5} \mathrm{M}^{-1}$, that have been attributed to the interactions with guanine-N7 sites and the backbone $\mathrm{PO}_{2}$ group, respectively. This mechanism of tRNA binding could explain the condensation phenomenon observed at high Co(III) content, as previously shown in the Co(III)-DNA complexes.
\end{abstract}

Keywords: tRNA; polyamines; preferential binding site; binding constant; hyperchromism; hypochromism; condensation; tRNA stability; FTIR spectroscopy; affinity capillary electrophoresis (ACE)

\section{INTRODUCTION}

The biogenic polyamines putrescine, spermidine, and spermine (Structure 1) are small aliphatic polycationic compounds present in almost all living organisms. They are essential for normal cell growth, and their concentrations increase with cell proliferation (Tabor and Tabor 1984; Cohen 1998; Igarashi and Kashiwagi 2000; Thomas and Thomas 2001; Childs et al. 2003). In mammalian cells, they are found in millimolar concentrations (Tabor and Tabor 1984; Cohen 1998; Igarashi and Kashiwagi 2000). Of the many hypotheses advanced to explain their biological effects, the most important one concerns their interaction with nucleic acids (Tabor

Abbreviations: Spm, spermine; Spd, spermidine; Put, putrescine; $\mathrm{Co}$ (III) cobalt(III)hexamine; CE, capillary electrophoresis; ACE, affinity capillary electrophoresis; FTIR, Fourier transform infrared; tRNA, transfer RNA; A, adenine; $\mathrm{G}$, guanine; $\mathrm{C}$, cytosine; $\mathrm{U}$, uracil; $r$, polyamine/tRNA(P) molar ratio.

Reprint requests to: Heidar-Ali Tajmir-Riahi, Department of ChemistryBiology, University of Québec at Trois-Rivières, Trois-Rivières (Québec) G9A 5H7, Canada; e-mail: tajmirri@uqtr.ca; fax: (819) 376-5084.

Article published online ahead of print. Article and publication date are at http://www.rnajournal.org/cgi/doi/10.1261/rna.1994310. and Tabor 1984; Feuerstein et al. 1991; Marton and Pegg 1995; Cohen 1998; Thomas and Thomas 2001). However, it seems that a large fraction of polyamines exists in polyamine-RNA adducts, and the major part of their cellular function may be explained through structural changes of RNA by polyamines (Watanabe et al. 1991; Cohen 1998; Igarashi and Kashiwagi 2000). On the other hand, the potential effectiveness of polyamine analogs, as antiproliferative agents against many tumor cell lines and infectious diseases, provides evidence for nucleic acid interaction with the biogenic polyamines ( $\mathrm{Li}$ et al. 1996; Frydman and Valasinas 1999; Fernandez et al. 2000; Bacchi et al. 2002; Thomas et al. 2002; Frydman et al. 2003; Thomas and Thomas 2003).

Interactions of polyamines with tRNA are less understood than they are with DNA, and thus, more specific theoretical and experimental studies of polyamine-tRNA bindings are required. The interactions of both spermine and spermidine with tRNA have been studied using solutions of ${ }^{1} \mathrm{H}-\mathrm{NMR}$ (Frydman et al. 1996, 1999), ${ }^{13}$ C-NMR (Frydman et al. 1990), and ${ }^{15} \mathrm{~N}-\mathrm{NMR}$ (Frydman et al. 1992; Fernandez et al. 1994). The authors observed that in all polyamines, internal $\mathrm{NH}_{2}{ }^{+}$ groups bind to tRNA more strongly than the terminal 


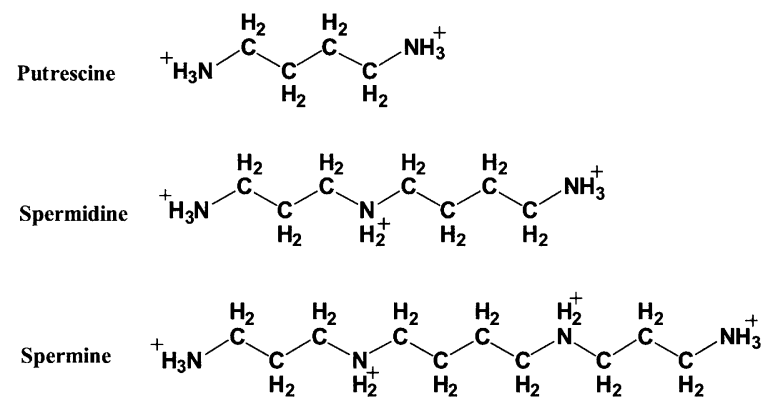

STRUCTURE 1. Chemical structures of biogenic polyamines putrescine, spermidine, and spermine.

$\mathrm{NH}_{3}{ }^{+}$groups. They suggest that factors other than the electrostatic interaction are responsible for this phenomenon, since the primary amines $\left(-\mathrm{NH}_{3}{ }^{+}\right)$possess a higher density of positive charge than the secondary ones $\left(-\mathrm{NH}_{2}{ }^{+}-\right)$. The ${ }^{15} \mathrm{~N}-\mathrm{NMR}$ experiments suggest that the specificity by which the nitrogen atoms in polyamines bind to tRNA is a consequence of the various hydrogen bonds that can be established between both tRNA and the polyamines (Frydman et al. 1992; Fernandez et al. 1994). Interestingly, other researchers (Bibillo et al. 1999) found that biogenic polyamines are required for the non-enzymatic cleavage of tRNA and oligoribonucleotides at UA and CA phosphodiester bonds. This suggests that at least two linked protonated amino groups are necessary to mediate hydrolysis. They hypothesized that one ammonium group binds to the nucleotide, while the second one participates in the activation of the labile phosphodiester bond (Quigley et al. 1978). However, in spite of these extensive studies, the binding sites of the biogenic polyamines on tRNA are not still clearly established.

A spermine-tRNA ${ }^{\text {Phe }}$ complex has been crystallized and its structure resolved at $2.5 \AA$ resolution (Quigley et al. 1978; Shi and Moore 2000). The polyamine binds at two major sites - the first in the major groove at the end of the anticodon stem and the second near the variable loop around phosphate 10 at a turn, in the RNA backbone. However, ${ }^{1} \mathrm{H}-\mathrm{NMR}$ studies found that spermine and related polyamines bind to additional sites of tRNA, in particular at the junction of the T $\psi \mathrm{C}$ - and D-loops, that were not seen in the crystal structure (Frydman et al. 1996, 1999). Binding of biogenic polyamines to tRNA has been shown to be relevant for optimal translational accuracy and efficiency (Igarashi and Kashiwagi 2000). They are found to modulate protein synthesis (Shimogori et al. 1996; Igarashi and Kashiwagi 2006) and influence the binding of deacylated and acylated tRNA to the ribosomes (Agrawal et al. 1999; Yoshida et al. 1999). These effects may be explained by the ability of polyamines to bind and influence secondary structure of tRNA, mRNA, and rRNA (Shimogori et al. 1996; Agrawal et al. 1999; Yoshida et al. 1999; Igarashi and Kashiwagi 2000, 2006).

Recently, we have published the results of infrared spectroscopy, capillary electrophoresis, and molecular modeling on the interaction between DNA and biogenic polyamines and cobalt(III)hexamine (Ahmed Ouameur and TajmirRiahi 2004). In our report, several binding models were proposed for biogenic polyamines, and their biological significances have been discussed. The aim of this work was to extend our knowledge pertaining to the effects of the polyamines on nucleic acids by studying the interactions of biogenic polyamines and cobalt(III)hexamine with tRNA, using capillary electrophoresis and Fourier transform infrared spectroscopy as well as molecular modeling, in order to establish a correlation between our results and the significance of the polyamine-tRNA complex formation in vivo. Cobalt(III)hexamine was included in this study (as a control model) because it is an inorganic polyamine cation known to bind RNA at the guanine N7 and at the phosphate oxygen atoms, in the major groove of the GAAA tetraloop (Kieft and Tinoco 1997; Rüdisser and Tinoco 1999). It has been shown that cobalt(III)hexamine induces DNA condensation and conformational transitions (Ahmed Ouameur and Tajmir-Riahi 2004).

\section{RESULTS}

\section{Interaction of polyamines with tRNA studied by FTIR spectroscopy}

The infrared spectra of tRNA solutions (Figs. 1, 2 first spectrum) were found to be similar to the double-stranded RNA and double-stranded DNA in A-form (Tsuboi 1970; Taillandier et al. 1985; Theophanides and Tajmir-Riahi 1985; Taillandier and Liquier 1992; Arakawa et al. 2001; Ahmed Ouameur et al. 2004a; Marty et al. 2004a). Table 1 summarizes the relevant frequencies and assignments of the main infrared bands of tRNA. Bands appearing between 1700 and $1550 \mathrm{~cm}^{-1}$ were assigned to the in-plane vibration of RNA bases. The strong infrared band at $1698 \mathrm{~cm}^{-1}$ was mainly assigned to the $\mathrm{C}=\mathrm{O}$ and $\mathrm{C}=\mathrm{N}$ stretching vibration from guanine residues (Arakawa et al. 2001; Ahmed Ouameur et al. 2004a; Marty et al. 2004a). Both the C6=O and C8=N7 bonds are located in the major groove of double-stranded tRNA; the N7 atom is the main target for cation-RNA binding, since it is not involved in the Watson-Crick hydrogenbond pairing. The second strong band at $1653 \mathrm{~cm}^{-1}$ was mainly assigned to the $\mathrm{C}=\mathrm{O}$ stretching vibration of uracil (Arakawa et al. 2001; Ahmed Ouameur et al. 2004b; Marty et al. 2004a). This band contains both $\mathrm{C} 2=\mathrm{O}$ and $\mathrm{C} 4=\mathrm{O}$ modes, and the major contribution to its intensity comes from the $\mathrm{C} 2=\mathrm{O}$ stretching vibration, which is not involved in the Watson-Crick hydrogen-bond pairing. The $\mathrm{C} 2=\mathrm{O}$ bond is located in the minor groove, while the $\mathrm{C} 4=\mathrm{O}$ bond is positioned in the major groove of the double-stranded tRNA. The band at $1608 \mathrm{~cm}^{-1}$ was assigned mainly to the adenine residues (Arakawa et al. 2001; Ahmed Ouameur et al. 2004b; Marty et al. 2004a). Theoretical calculations for the adenine vibrational frequencies (Dhaoudi et al. 1993) demonstrated 


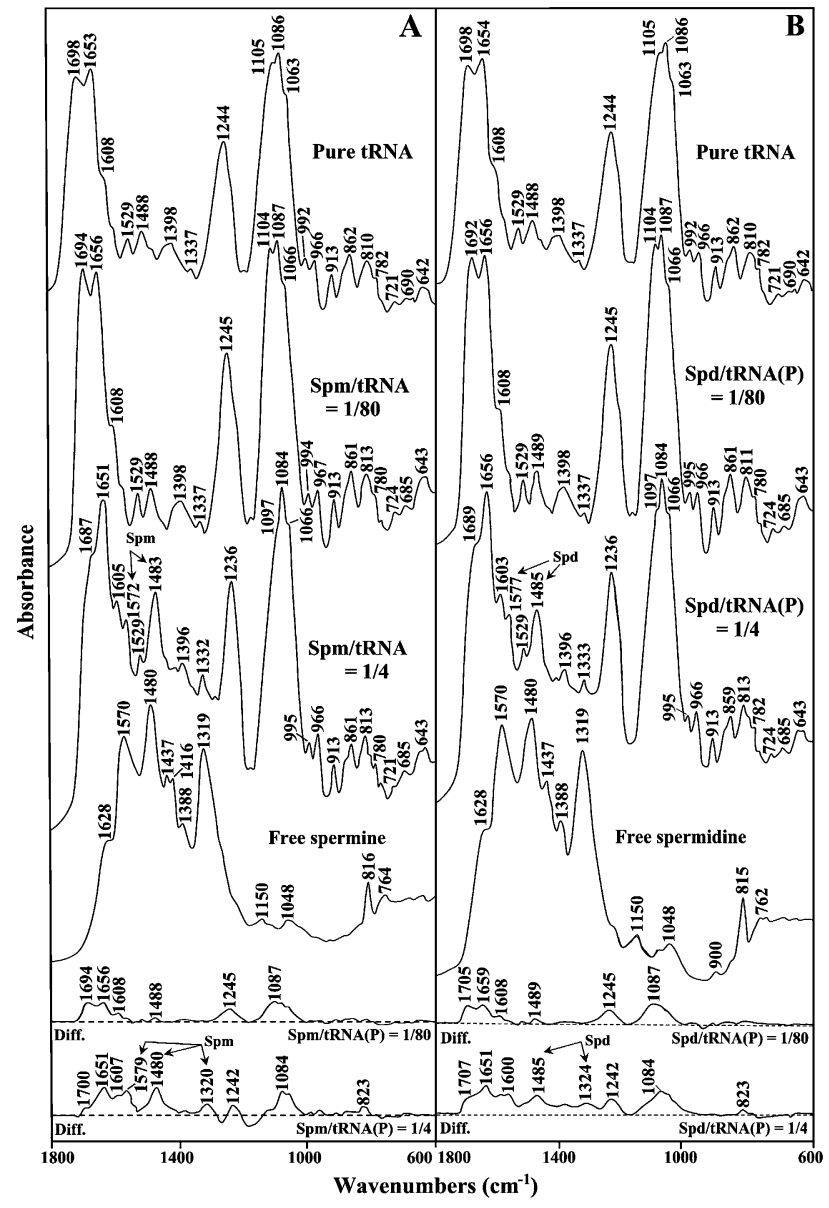

FIGURE 1. FTIR spectra in the region of $1800-600 \mathrm{~cm}-1$ for pure tRNA, free polyamine, spermine-tRNA $(A)$, and spermidine-tRNA $(B)$ adducts in aqueous solution at $\mathrm{pH} 7.0 \pm 0.2$ (top three spectra) and difference spectra for polyamine-tRNA adducts obtained at various polyamine/tRNA(P) molar ratios (bottom two spectra).

that the normal mode for the band at $1608 \mathrm{~cm}^{-1}$ contained major contributions from N7, N9, and N3 atoms. The N7 and $\mathrm{N} 3$ atoms are the main sites for cation interaction and are located in the major and the minor grooves of the tRNA duplex, respectively.

Other infrared bands related to RNA vibrations were examined in the region between 1550 and $1250 \mathrm{~cm}^{-1}$. These absorptions were assigned to the in-plane ring vibration of the bases and contain some marker of A-form RNA (Tsuboi 1970; Arakawa et al. 2001; Ahmed Ouameur et al. 2004a; Marty et al. 2004a). The most important absorption is located at $1488 \mathrm{~cm}^{-1}$, which is attributed to cytosine in-plane ring vibration (Tsuboi 1970; Arakawa et al. 2001; Ahmed Ouameur et al. 2004a; Marty et al. 2004a). Other vibrations at $1529 \mathrm{~cm}^{-1}$ (cytosine), $1398 \mathrm{~cm}^{-1}$ (guanine in anti conformation), and $1337 \mathrm{~cm}^{-1}$ (adenine and uracil) are related to the G-C and A-U base pairs (Tsuboi 1970; Arakawa et al. 2000; Ahmed Ouameur et al. 2004b; Marty et al. 2004a).

The backbone phosphate group vibrational frequencies appeared as strong bands in the region $1250-1080 \mathrm{~cm}^{-1}$ of the tRNA spectrum (Figs. 1, 2 first spectrum). The two strong absorption bands located at 1244 and $1086 \mathrm{~cm}^{-1}$ were assigned mainly to the asymmetric and symmetric stretching vibrations of the $\mathrm{PO}_{2}{ }^{-}$groups, respectively (Taillandier et al. 1984a,b, 1985; Taillandier and Liquier 1992; Dhaoudi et al. 1993; Arakawa et al. 2001). The spectral region of 1080$800 \mathrm{~cm}^{-1}$ contains several infrared marker bands of tRNA in A-conformation, corresponding to the phosphodiester chain coupled with the ribose vibrational modes (Tsuboi 1970; Taillandier et al. 1985; Theophanides and TajmirRiahi 1985; Taillandier and Liquier 1992). Finally, several absorption bands in the region of $800-600 \mathrm{~cm}^{-1}$ were attributed to the out-of-plane ring modes of the tRNA bases: $782 \mathrm{~cm}^{-1}$ (pyrimidine), $721 \mathrm{~cm}^{-1}$ (adenine), $690 \mathrm{~cm}^{-1}$ (guanine), and $642 \mathrm{~cm}^{-1}$ (uracil) (Tsuboi 1970; Taillandier et al. 1985; Theophanides and Tajmir-Riahi 1985; Taillandier and Liquier 1992).

\section{Infrared spectra of tRNA-polyamine complexes at low polycation concentration}

The FTIR spectral features of tRNA-polyamine complexes between 1800 and $600 \mathrm{~cm}^{-1}$ are presented in Figures 1 and 2. Molar ratios from $1 / 80$ to $1 / 4$ were studied for spermine,

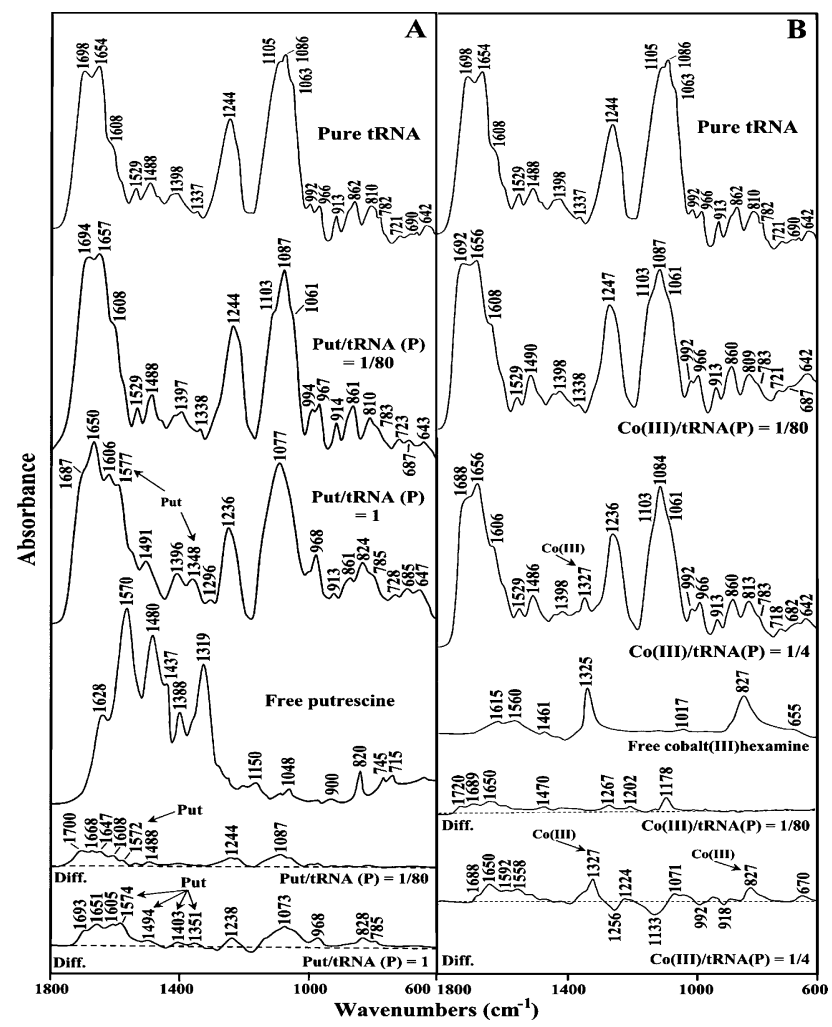

FIGURE 2. FTIR spectra in the region of $1800-600 \mathrm{~cm}^{-1}$ for pure tRNA, free polyamine, putrescine-tRNA $(A)$, and cobalt(III)hexaminetRNA $(B)$ adducts in aqueous solution at pH 7.0 \pm 0.2 (top three spectra) and difference spectra for polyamine-tRNA adducts obtained at various polyamine/tRNA(P) molar ratios (bottom two spectra). 
TABLE 1. Measured wave numbers, relative intensities, and assignments for the main infrared bands of Baker's yeast tRNA in aqueous solution at $\mathrm{pH} 7.0 \pm 0.2$

\section{Wave number}

$\left(\mathrm{cm}^{-1}\right)$ Intensity ${ }^{\mathrm{a}}$

Assignment $^{\mathrm{b}}$

\begin{tabular}{lc}
\hline 1698 & VS \\
1653 & VS \\
1608 & S \\
1529 & W \\
1488 & M \\
1398 & S \\
1244 & VS \\
1086 & VS \\
1063 & S \\
966 & $M$ \\
913 & $M$ \\
862 & $M$ \\
810 & $M$
\end{tabular}

a Relative intensities: (S) strong, (VS) very strong, (M) medium, (W) weak.

${ }^{\mathrm{b}}$ Assignments have been taken from the literature, and relevant references are given in the Results section. spermidine, and cobalt(III)hexamine. Higher concentrations could not be investigated due to tRNA precipitation. For putrescine, molar ratios up to 1 were studied without precipitation under our experimental settings. Similar concentrations were also used for polyamine-calf-thymus DNA complexes (Ahmed Ouameur and Tajmir-Riahi 2004). These ranges are physiologically justified since millimolar concentrations of polyamines have been found in the nucleus of eukaryotic cells (Gosule and Schellman 1976).

Important shifting of the absorption bands of pure tRNA was observed in the region $\left(1700-1550 \mathrm{~cm}^{-1}\right)$, upon polyamine complexation. The bands at $1698 \mathrm{~cm}^{-1}$ (guanine $\mathrm{C} 7=\mathrm{N}, \mathrm{C} 6=\mathrm{O}$ ) and $1653 \mathrm{~cm}^{-1}$ (uracil C=O) were shifted by several wave numbers $\left(3-6 \mathrm{~cm}^{-1}\right)$ upon the interactions with biogenic polyamines and cobalt(III)hexamine (Figs. $1,2, r=1 / 80)$. The shifting was associated with increase in relative intensities. The most important increase in intensity was observed mainly for a guanine band at $1698 \mathrm{~cm}^{-1}(10 \%-17 \%)$ and uracil band at $1653 \mathrm{~cm}^{-1}(10 \%-13 \%)$ (Fig. 3, $r=$ $1 / 80$ to $1 / 40)$. The adenine vibration at $1608 \mathrm{~cm}^{-1}$ exhibited no shifting and no major intensity changes at low polyamine concentrations (Figs. 1-3). The spectral features observed in the difference spectra of the polyamine-tRNA complexes are consistent with the mentioned spectral changes (Figs. 1, 2, diff. spectra). The positive bands at $1694 \mathrm{~cm}^{-1}$ and $1656 \mathrm{~cm}^{-1}$ (Spm-tRNA diff. spectra);
$1705 \mathrm{~cm}^{-1}$ and $1659 \mathrm{~cm}^{-1}$ (Spd-tRNA diff. spectra); $1700 \mathrm{~cm}^{-1}$ and $1668 \mathrm{~cm}^{-1}$ (Put-tRNA diff. spectra); and $1720 \mathrm{~cm}^{-1}$, $1689 \mathrm{~cm}^{-1}$, and $1650 \mathrm{~cm}^{-1}$ [Co(III)tRNA diff. spectra] are attributed to the interaction of polycation with guanine $(\mathrm{C} 6=\mathrm{O}, \mathrm{C}=\mathrm{N} 7)$ and uracil $(\mathrm{C}=\mathrm{O})$ reactive sites, respectively. No major spectral differences were observed for the adenine band $\left(1608 \mathrm{~cm}^{-1}\right)$ in the difference spectra of the polyamine-tRNA adducts, which indicates no participation of adenine in the polycation-tRNA binding (Figs. 1, 2).

Other tRNA vibrational frequencies in the region of $1550-1250 \mathrm{~cm}^{-1}$ (in-plane ring vibration of the bases) showed minor spectral changes upon polyamine interaction. No major spectral shifting was observed for the bands at $1529 \mathrm{~cm}^{-1}$ ( $\mathrm{G}$ and C), $1488 \mathrm{~cm}^{-1}$ (mainly C), $1398 \mathrm{~cm}^{-1}(\mathrm{G})$, and $1337 \mathrm{~cm}^{-1}$ (C) (Figs. 1, 2). In addition, the relative intensity of the cytosine band $\left(1488 \mathrm{~cm}^{-1}\right)$ did not change significantly at low biogenic polyamine concentrations (Fig. 3A-C). In the case of cobalt(III)hexamine, the band $1488 \mathrm{~cm}^{-1}$ was shifted upward by $2 \mathrm{~cm}^{-1}$ (Fig. 2B), which is due to the effect of the cobalt guanine N7 binding on the $\mathrm{G}-\mathrm{C}$ vibrational modes. This finding was supported by the positive feature at $1470 \mathrm{~cm}^{-1}$ observed in the difference spectra of cobalt(III)hexamine-tRNA adducts (Fig. 2B).
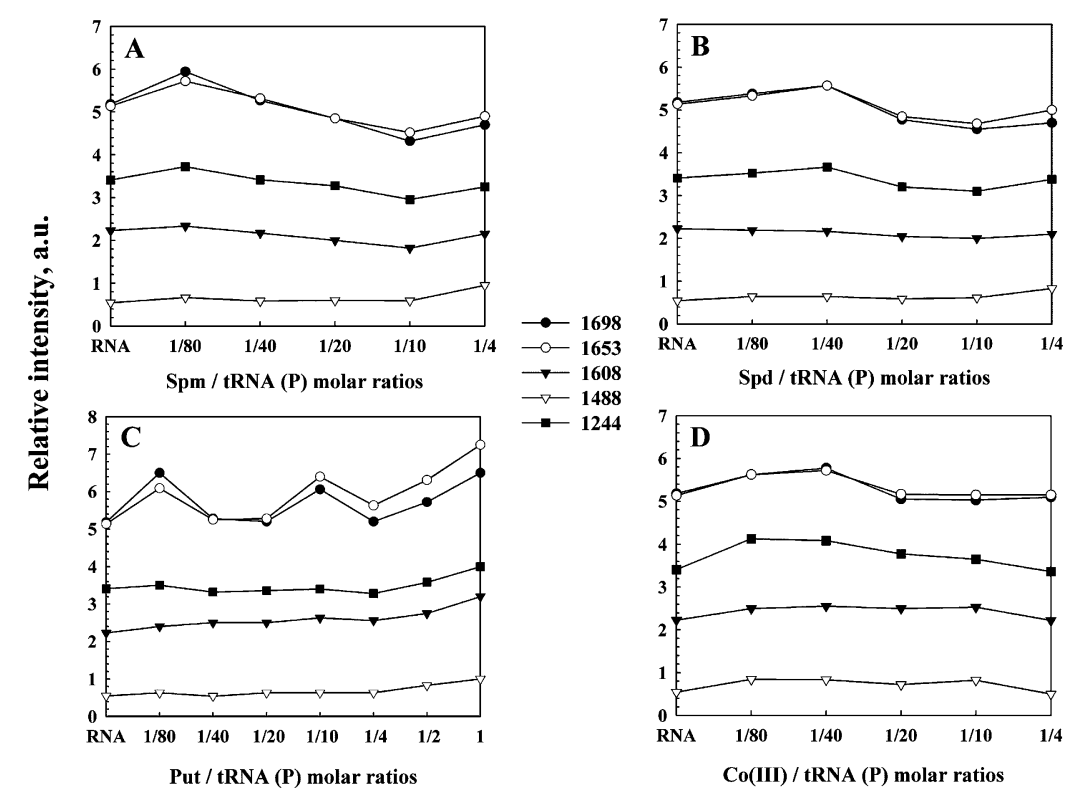

FIGURE 3. Relative intensity variations in arbitrary units for several tRNA in-plane vibrations as a function of polyamine concentration. $(A-D)$ Relative intensity for the tRNA bands at 1698 (guanine), 1653 (uracil), 1608 (adenine), 1488 (cytosine), and $1244 \mathrm{~cm}^{-1}\left(\mathrm{PO}_{2}^{-}\right)$for spermine, spermidine, putrescine, and cobalt(II1I)hexamine, respectively. 
In the phosphate region (1250-1080 $\left.\mathrm{cm}^{-1}\right)$, only cobalt(III)hexamine induced appreciable shifting $\left(3 \mathrm{~cm}^{-1}\right)$ for the band at $1244 \mathrm{~cm}^{-1}$ (asymmetric $\mathrm{PO}_{2}{ }^{-}$stretch), whereas the band at $1086 \mathrm{~cm}^{-1}$ (symmetric $\mathrm{PO}_{2}{ }^{-}$stretch) shifted by only $1 \mathrm{~cm}^{-1}$. As for the biogenic polyamines, the phosphate bands did not show considerable shifting, while intensity changes were observed. However, three new bands at $1267 \mathrm{~cm}^{-1}, 1202 \mathrm{~cm}^{-1}$, and $1178 \mathrm{~cm}^{-1}$ appeared in the difference spectra of cobalt(III)hexamine (Fig. 2B). This indicates a weaker interaction of the biogenic polyamines with the phosphate groups than that of cobalt(III)hexamine cation.

In our previous study on polyamine-DNA interactions, we found no evidence suggesting the interaction between the polyamines and deoxyribose (Ahmed Ouameur and Tajmir-Riahi 2004). However, by examining the spectral region $1100-800 \mathrm{~cm}^{-1}$ of the polyamine-tRNA complexes, we observed some spectral perturbations, upon polyamine complexation. In fact, the band at $1063 \mathrm{~cm}^{-1}$ (C-O ribose stretch) shifts by $2-3 \mathrm{~cm}^{-1}$ in all four polyamine-tRNA complexes. In addition, the bands $992 \mathrm{~cm}^{-1}$ (C-C ribose stretch) and $862 \mathrm{~cm}^{-1}$ (ribose-phosphodiester bound) shift by $2-3 \mathrm{~cm}^{-1}$ in the biogenic polyamine-tRNA and cobalt(III)hexamine-tRNA complexes, respectively (Figs. 1, 2). The spectral changes observed can be attributed to a minor polycation interaction with the ribose moiety. Polyamine interactions with ribose $2^{\prime}-\mathrm{OH}$ were previously noted in a series of polycation-tRNA complexes (Bolton and Kearns 1978). However, the polycation-ribose interaction is more pronounced at high biogenic polyamine concentrations (discussed below).

Other tRNA vibrational frequencies in the region of 800 $600 \mathrm{~cm}^{-1}$ showed minor spectral changes upon polyamine complexation. Bands appearing in this region were assigned to the out-of-plane vibration of the bases (Tsuboi 1970; Taillandier et al. 1984a; Theophanides and Tajmir-Riahi 1985). The band at $782 \mathrm{~cm}^{-1}$ (pyrimidine) shifted by $2 \mathrm{~cm}^{-1}$ after addition of spermine and spermidine, while it changed only by $1 \mathrm{~cm}^{-1}$ in the case of putrescine and cobalt(III)hexamine cations (Figs. 1, 2). The band at $721 \mathrm{~cm}^{-1}$ (adenine) shifted by $2-3 \mathrm{~cm}^{-1}$ upon addition of biogenic polyamines, which is indicative of other sites than N7 participation in cation interaction. The adenine-N3 site, located in the minor groove of the double helix region, could be a good target since it is not involved in the Watson-Crick network of basepairing. Finally, the band at $690 \mathrm{~cm}^{-1}$ (guanine) shifted downward by several wave numbers $\left(\mathrm{cm}^{-1}\right)$ in all four polyamine-tRNA complexes (Figs. 1, 2). Furthermore, the infrared spectra of spermine and spermidine (Fig. 3A,B) at molar ratios between $1 / 40$ and $1 / 10$ show a general decreasing (hypochromism) in intensity of the bands at 1698, 1653, 1608 , and $1244 \mathrm{~cm}^{-1}$. This fact has been attributed to the increase in the base-stacking and base-pairing as a consequence of nucleic acid stabilization (Ahmed Ouameur and Tajmir-Riahi 2004).

\section{Infrared spectra of tRNA-polyamine complexes at high polycation concentration}

Major spectral changes were observed at high polyamine concentrations. As polycation concentration increased $(r=1 / 4)$, larger frequency shifting was observed in the double-bond region. The strong band at $1698 \mathrm{~cm}^{-1}$ (guanine, $\mathrm{C}=\mathrm{O} / \mathrm{N} 7)$ shifted downward by several wave numbers $\left(\mathrm{cm}^{-1}\right)$ in the spectra of all four polycations (Figs. 1,2). This result indicates that the preferential binding site for the polycations is the N7-guanine site, since the $\mathrm{O} 6$ is involved in the Watson-Crick network of base-pairing. Other bands at $1653 \mathrm{~cm}^{-1}(\mathrm{U}, \mathrm{C}=\mathrm{O} 2 / \mathrm{O} 4)$ and $1608 \mathrm{~cm}^{-1}$ (A, C=N7) also shifted appreciably $\left(2-5 \mathrm{~cm}^{-1}\right)$ at high polycation concentration (Figs. 1, 2). These results are supported by the infrared difference spectra showed in the bottom of Figures 1 and 2 . The positive features at 1700, 1651, and $1607 \mathrm{~cm}^{-1}$ (for spermine) - 1707, 1651, and $1600 \mathrm{~cm}^{-1}$ (for spermidine); 1693,1651 , and $1605 \mathrm{~cm}^{-1}$ (for putrescine); and 1688, 1650, and $1592 \mathrm{~cm}^{-1}$ [for cobalt(III)hexamine] - are attributed to the polycation interactions with guanine-N7, uracil-O2, and adenine-N7 reactive sites, respectively (Figs. 1, 2).

Figure $3 \mathrm{C}$ shows the relative intensity changes of the IR marker bands in the presence of putrescine at various polycation concentrations. An important increase in intensity of the marker bands appears when the polyamine concentration increased to a maximum at high putrescine concentration $(r=1)$. This increase in intensity is called the hyperchromic effect (Pavia et al. 1979), and it is provoked by the base unstaking and unpairing as a consequence of the helix destabilization (Fichera et al. 2000). At high polyamine content, the helix opening contributed to putrescine binding to the single-stranded region, such as the loop of the tRNA molecule. However, the hyperchromic effect for spermine and spermidine was not observed since the maximum concentration used is at molar ratio $r=1 / 4$ (to avoid precipitation).

The infrared spectra at higher concentrations studied in each case allowed us to detect new bands between 1600 and $1300 \mathrm{~cm}^{-1}$ for the biogenic polyamine-tRNA complexes. In fact, the bands measured at 1572,1483 , and $1332 \mathrm{~cm}^{-1}$ for spermine; 1577,1485 , and $1333 \mathrm{~cm}^{-1}$ for spermidine; and 1577, 1491, and $1348 \mathrm{~cm}^{-1}$ for putrescine (Figs. 1, 2) were assigned to the $\mathrm{N}-\mathrm{H}$ bending vibration of the $\mathrm{NH}_{3}{ }^{+}$groups, methylene scissoring vibrations, and symmetric bending mode of methyl groups, respectively (Pavia et al. 1979; Gunzler and Gremlich 2002). These bands shifted by 3-11 $\mathrm{cm}^{-1}$ with respect to the infrared spectra of the free polyamines (Figs. 1,2), supporting an active participation of the primary amino groups in the interaction and the existence of the hydrophobic contact with the methyl groups of tRNA. The positive features measured in the difference spectra of each biogenic polyamine, namely, 1579,1480 , and $1320 \mathrm{~cm}^{-1}$ (spermine); 1485 and $1324 \mathrm{~cm}^{-1}$ (spermidine); and 1574 , 1494 , and $1351 \mathrm{~cm}^{-1}$ (putrescine) support the polycation interactions (hydrogen binding, hydrophobic contact) with the 
polynucleotide. The new band measured at $1327 \mathrm{~cm}^{-1}$, in the infrared spectra of the Co(III)-tRNA complex at high cobalt(III)hexamine content (Fig. 2B), is assigned to the $\mathrm{NH}_{3}$ symmetric deformation mode of cobalt(III)hexamine (Nakamoto 1997) and is not arising from tRNA vibration, which suggests that cobalt might bind tRNA by hydrogenbonding.

The interaction between the polyamines and the backbone phosphate groups is evident by the shifting of the bands at $1244 \mathrm{~cm}^{-1}\left(v_{\mathrm{as}} \mathrm{PO}_{2}{ }^{-}\right)$and $1088 \mathrm{~cm}^{-1}\left(v_{\mathrm{s}} \mathrm{PO}_{2}{ }^{-}\right)$by several wave numbers $\left(\mathrm{cm}^{-1}\right)$ at higher polyamine concentrations. The positive features in the difference spectra at 1242 and $1084 \mathrm{~cm}^{-1}$ (spermine and spermidine), at 1238 and 1073 $\mathrm{cm}^{-1}$ (putrescine), and 1224 and $1071 \mathrm{~cm}^{-1}$ [ cobalt(III)hexamine] are due to the polycation-phosphate interactions (Figs. 1, 2). The negative bands observed in the phosphate $\left(1256 \mathrm{~cm}^{-1}\right)$ and ribose $\left(1133,992\right.$, and $\left.918 \mathrm{~cm}^{-1}\right)$ regions of the difference spectra of cobalt(III)hexamine indicate a minor amount of tRNA condensation. Major DNA condensation was observed upon cobalt(III)hexamine-DNA complexation at high polycation content (Ahmed Ouameur and Tajmir-Riahi 2004).

The spectral changes observed in the region of 1080-800 $\mathrm{cm}^{-1}$ exhibit polycation interaction with the ribose moiety of tRNA. The bands at 1100, 1066, 995, and $968 \mathrm{~cm}^{-1}$ assigned to the ribose $\mathrm{C}-\mathrm{O}$ and $\mathrm{C}-\mathrm{C}$ ribose modes showed major spectral shifting upon biogenic polyamine complexations. At high polycation content, the band at $1105 \mathrm{~cm}^{-1}$ lost its intensity and shifted toward a lower frequency at $1097 \mathrm{~cm}^{-1}$ (Figs. 1, 2). Similarly, the band at $1063 \mathrm{~cm}^{-1}$ was observed at $1066 \mathrm{~cm}^{-1}$ in the spectra of spermine-tRNA and spermidine-tRNA adducts (Fig. 1). The spectral changes were less pronounced for the cobalt(III)hexamine-tRNA complexes. This indicates some degree of polycation-ribose interaction (H-bonding) upon polyamine complexation. However, the bindings of the polycations to biopolymer did not induce tRNA conformational changes. In fact, there was no major shifting of the A-form tRNA marker bands such as 810 and
$862 \mathrm{~cm}^{-1}$ (ribose-phosphodiester) upon polycation adduct formation. This indicated that tRNA remains in the A-family structure in these polyamine-tRNA complexes.

\section{Interaction of polyamines with tRNA studied by capillary electrophoresis}

Capillary electrophoresis was used to examine further the interaction of polycations with tRNA. In Table 2 , the experimental data related to the migration times of pure tRNA and its complexes with biogenic polyamines and cobalt(III)hexamine at different polycation concentrations are shown.

The saturation curve (Fig. 4A) shows a change in the migration time of tRNA after addition of different polycation concentrations. As polycation concentration reached 12.5 $\mu \mathrm{M}$ for spermine, $25 \mu \mathrm{M}$ for spermidine and cobalt(III)hexamine, and $50 \mu \mathrm{M}$ for putrescine (Table 2), no appreciable changes were measured for the polycation-tRNA complexes. Based on these results, binding constants of the polycationtRNA complexes were determined by Scatchard analysis, as described in Materials and Methods. Scatchard analysis for the biogenic polyamine-tRNA adducts showed one overall binding constant for each polyamine, namely, $K_{\mathrm{Spm}}=8.7 \times$ $10^{5} \mathrm{M}^{-1}, K_{\text {Spd }}=6.1 \times 10^{5} \mathrm{M}^{-1}$, and $K_{\text {Put }}=1.0 \times 10^{5} \mathrm{M}^{-1}$ (Fig. 4B). The stability was in the order spermine > spermidine $>$ putrescine. This finding is in agreement with the NMR studies (Frydman et al. 1990, 1992, 1996, 1999; Fernandez et al. 1994) that found the secondary amino groups $\left(-\mathrm{NH}_{2}{ }^{+}\right)$of polyamine bind more strongly than the primary amino groups $\left(-\mathrm{NH}_{3}{ }^{+}\right)$. In fact, spermine contains two $-\mathrm{NH}_{2}{ }^{+}$- groups, spermidine one group, while putrescine does not contain a secondary amino group. Scatchard analysis of the data for the cobalt(III)hexamine-tRNA complexes showed high- and low-affinity sites with binding constants of $K_{1}=3.2 \times 10^{5} \mathrm{M}^{-1}$ and $K_{2}=1.7 \times 10^{5} \mathrm{M}^{-1}$, respectively (Fig. $4 \mathrm{C}$ ). These results suggest that cobalt(III)hexamine binds at two distinct binding sites on the tRNA molecule. Furthermore, it may be speculated that the

TABLE 2. Experimental values of the migration time of pure tRNA and polyamine-tRNA adducts following incubation of a constant concentration of tRNA $(1.25 \mathrm{mM})$ with various concentrations of polyamines

\begin{tabular}{|c|c|c|c|c|c|c|c|}
\hline \multicolumn{2}{|c|}{ Spermine } & \multicolumn{2}{|c|}{ Spermidine } & \multicolumn{2}{|c|}{ Putrescine } & \multicolumn{2}{|c|}{ Cobalt(III)hexamine } \\
\hline $\begin{array}{l}\text { Concentration } \\
(\mu \mathrm{M})\end{array}$ & $\begin{array}{l}\text { Migration time } \\
\quad(\min )\end{array}$ & $\begin{array}{c}\text { Concentration } \\
(\mu \mathrm{M})\end{array}$ & $\begin{array}{l}\text { Migration time } \\
\quad(\min )\end{array}$ & $\begin{array}{c}\text { Concentration } \\
(\mu \mathrm{M})\end{array}$ & $\begin{array}{l}\text { Migration time } \\
\qquad(\min )\end{array}$ & $\begin{array}{c}\text { Concentration } \\
(\mu \mathrm{M})\end{array}$ & $\begin{array}{l}\text { Migration time } \\
(\min )\end{array}$ \\
\hline 0 & 3.28 & 0 & 3.48 & 0 & 3.615 & 0 & 3.483 \\
\hline 1.563 & 3.212 & 1.563 & 3.365 & 1.563 & 3.636 & 1.563 & 3.546 \\
\hline 3.125 & 3.193 & 3.125 & 3.315 & 3.125 & 3.652 & 3.125 & 3.579 \\
\hline 6.25 & 3.177 & 6.25 & 3.29 & 6.25 & 3.67 & 6.25 & 3.6 \\
\hline 12.5 & 3.167 & 12.5 & 3.273 & 12.5 & 3.7 & 12.5 & 3.625 \\
\hline 25 & 3.164 & 25 & 3.248 & 25 & 3.725 & 25 & 3.65 \\
\hline 50 & 3.164 & 50 & 3.245 & 50 & 3.75 & 50 & 3.667 \\
\hline 100 & 3.165 & 100 & 3.24 & 100 & 3.761 & 100 & 3.685 \\
\hline 200 & 3.163 & 200 & 3.25 & 200 & 3.765 & 200 & 3.677 \\
\hline
\end{tabular}

Incubations were carried out in the run buffer $(20 \mathrm{mM}$ Tris- $\mathrm{HCl}$ at $\mathrm{pH} 7.0 \pm 0.2)$ for $30 \mathrm{~min}$ at $25^{\circ} \mathrm{C}$ prior to capillary electrophoresis. 

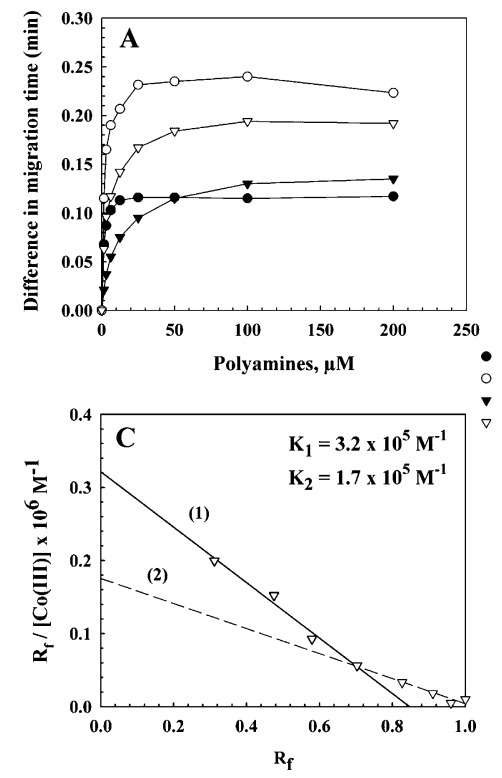

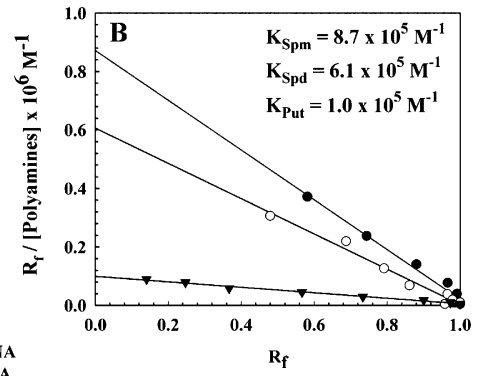

Spd-tRNA
Put-tRNA Co(III)-tRN

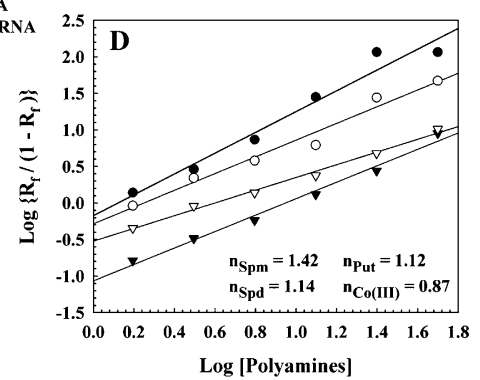

FIGURE 4. (A) Plot of the difference in migration time (in minutes) of polyamine-tRNA complexes from capillary electrophoresis following incubation of a constant concentration of tRNA $(1.25 \mathrm{mM})$ with various concentrations of polyamines. The difference in migration time of the polyamine-tRNA complexes was determined by subtracting the migration time of pure tRNA from that of each polyamine-tRNA adducts. $(B, C)$ Scatchard plots for biogenic polyamine-tRNA, and cobalt(III)hexamine-tRNA complexes, respectively. $(D)$ Hill plots for polyamine-tRNA complexes.

stronger interaction is due to the guanine-N7 atom, while the weaker binding is due to the polycation-phosphate oxygen atom, which is consistent with our infrared data and other studies (Kieft and Tinoco 1997; Rüdisser and Tinoco 1999).

The analysis of the cooperativity of the binding process between the polyamines and tRNA has been done (Fig. 4D). The Hill coefficients $n$ calculated for the biogenic polyamines were $1.42,1.14$, and 1.12 , for spermine, spermidine, and putrescine, respectively. Since the values obtained were $>1$, this means a positive cooperativity binding of biogenic polyamines with tRNA (Jack 1995). In contrast, the Co(III)-tRNA interaction was characterized by a negative cooperativity $(n<1)$ (Fig. 4D). Our data on the binding parameters of the four polycations to tRNA are comparable to that measured for polyamine-DNA complexes (Ahmed Ouameur and Tajmir-Riahi 2004). This finding may reflect some common molecular mechanism for DNA and tRNA binding. Undoubtedly, one of the most important roles of these polyamines in vivo is to stabilize the nucleic acids.

\section{Docking study}

Our results from FTIR and capillary electrophoresis are accompanied by docking experiments in which the putrescine, spermidine, and spermine cations were docked to tRNA to determine the preferred binding sites on tRNA. The dockings results are shown in Figure 5 and Table 3. The models show that putrescine is surrounded by A9, A23, G24, A26, G43, A44, and G45 with a binding energy of $-4.04 \mathrm{kcal} /$

mol (Fig. 5A; Table 3). Spermidine is located in the vicinity of A23, G24, A25, G26, C27, G43, A44, and G45 with the binding energy of $-3.81 \mathrm{kcal} / \mathrm{mol}$ (Fig. 5B; Table 3). However, spermine is positioned near A23, G4, A25, G26, C27, G43, A44, and G45 with the binding energy of $-3.57 \mathrm{kcal} / \mathrm{mol}$ (Fig. 5C; Table $3)$. The docking results showed most of the binding sites used are similar for these biogenic polyamines (Table 3 ). The binding energy $(\Delta G)$ shows the stability of the complexes formed: putrescine $>$ spermidine $>$ spermine (Table 3 ).

\section{DISCUSSION}

Interactions between biogenic polyamines and DNA have been extensively studied by several investigators using different methods (for reviews, see Feuerstein et al. 1991; Marton and Pegg 1995; Igarashi and Kashiwagi 2000; Thomas and Thomas 2001). Our recent report was related to the mechanism of spermine-, spermidine-, and putrescineDNA interactions (Ahmed Ouameur and Tajmir-Riahi 2004). In this study, several binding models have been proposed, in order to support preferential binding sites of polyamines in the major and/or the minor grooves of DNA. It seems that most of the intracellular polyamines are mainly associated with RNA molecules (Igarashi and Kashiwagi 2000). In recent years, the effects of polyamines on cell growth and the dependency of drug potency on polyamines have been well investigated (Bachrach 2005; Kouvela et al. 2006). However, limited studies have been done to understand the mechanism of polyamine-tRNA binding at molecular levels. In the present study, our interest was to determine the preferential binding sites of polyamines on tRNA.

One of the main conclusions arising from the spectroscopic analyses is that at low concentrations, spermine and spermidine were capable of stabilizing the structure of tRNA. This is evidenced by a decrease in intensity of several tRNA infrared bands (hypochromic effect). This effect has been observed at higher polyamine concentrations in the case of spermine- and spermdine-DNA complexes (Ahmed Ouameur and Tajmir-Riahi 2004). Since the hypochromism effect was observed at a higher molar ratio (1/4) in the polyamine-DNA complexes (Ahmed Ouameur and TajmirRiahi 2004), we concluded that at low concentration, spermine and spermidine are more effective in binding tRNA than DNA. In this way, spermine and spermidine could stabilize tRNA structure at low cation content, while highly polymerized calf-thymus DNA was stabilized at high polyamine concentrations (Ahmed Ouameur and Tajmir-Riahi 


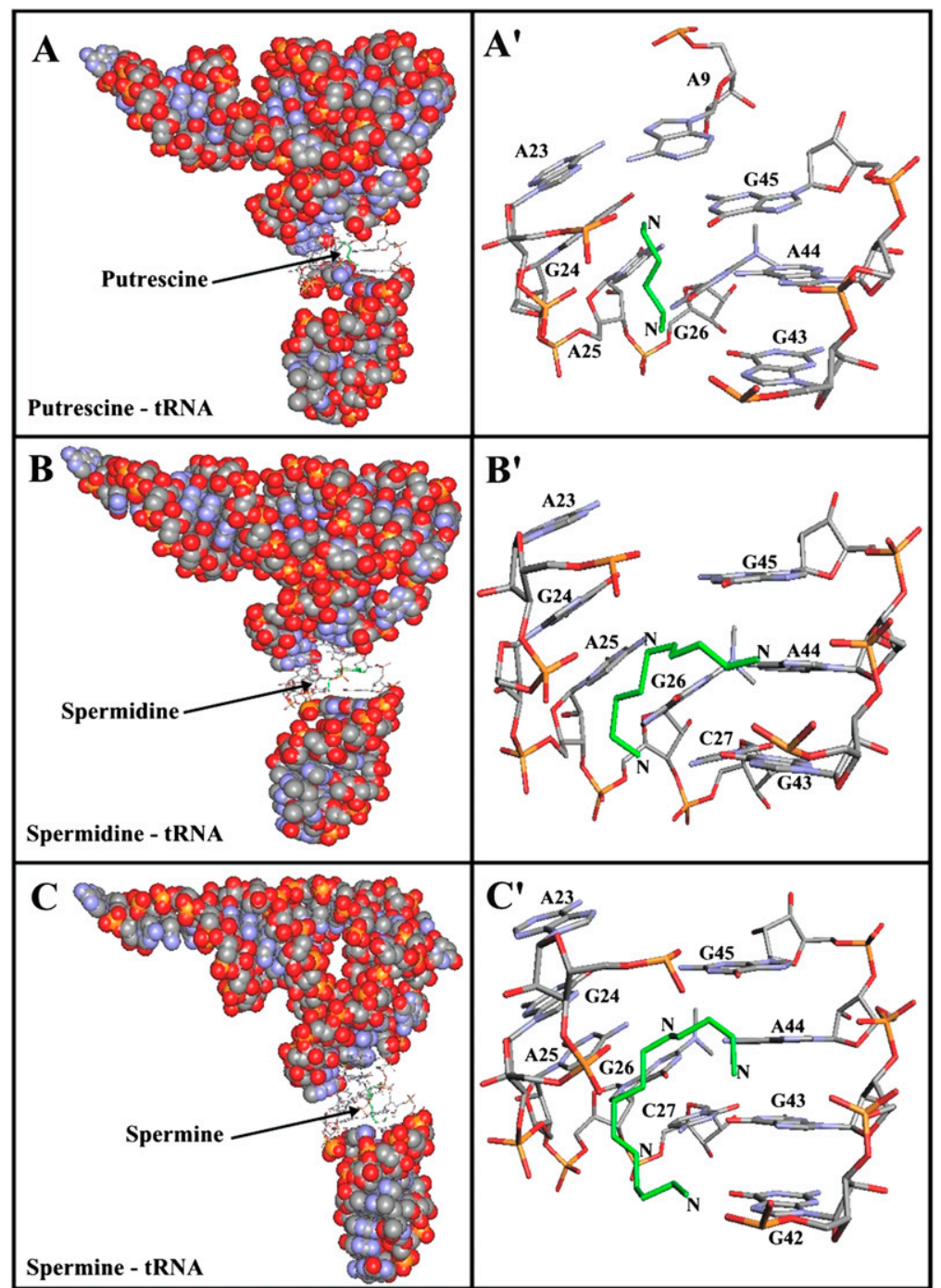

FIGURE 5. Best conformations for polyamines docked to tRNA (PDB entry 6TNA). (Green) The polyamines. $(A)$ tRNA in sphere-filling model with the putrescine binding site in sticks; $\left(A^{\prime}\right)$ putrescine binding sites represented in sticks with the corresponding base residues. $(B)$ tRNA in sphere-filling model with the spermidine binding site in sticks; $\left(B^{\prime}\right)$ spermidine binding sites represented in sticks. $(C)$ tRNA in sphere-filling model with the spermine binding sites represented in sticks; $\left(C^{\prime}\right)$ the binding sites represented in sticks.

2004). It has been shown that protein synthesis was stimulated at low polyamine (spermidine) concentration (Shimogori et al. 1996). This result is in accordance with our finding that tRNA molecules are stabilized at low polyamine concentration. This result also suggests that polyamine increases the binding of Met-tRNA to the ribosome subunits (Shimogori et al. 1996), which could be a consequence of polyamine binding to tRNA with an increase in RNA stability. At high polyamine concentrations, the hyperchromic effect (an increase in intensity of several infrared bands) was observed only in the putrescine-tRNA complex, due to helix destabilization. It has been found that higher concentrations of polyamine are inhibitory for the protein synthesis (Shimogori et al. 1996). The hyperchromic effect observed at high putrescine concentration could explain the inhibition of protein synthesis at high polyamine concentration. For spermine and spermidine, the hyperchromic effect was not observed since the maximum concentration used is at molar ratio $1 / 4$, in order to ovoid precipitation.

In addition, the data from infrared spectra have allowed us to analyze the polyamine-tRNA interactions at a molecular level. The preferential binding sites are slightly different from those of polyamineDNA complexes (Ahmed Ouameur and Tajmir-Riahi 2004). At low polyamine content, the interaction involves RNA bases and ribose moiety. The preferential binding sites are guanine-N7/O6, uracil$\mathrm{O} 2 / \mathrm{O} 4$, and adenine- $\mathrm{N} 3$ reactive sites. The interaction with the $2^{\prime}-\mathrm{OH}$ of the ribose is less pronounced than observed at high polyamine content. The cobalt(III)hexamine preferential binding sites are guanine-N7, uracil-O2, and cytosine-O2/N4 reactive sites and the backbone phosphate groups. At high polycation concentrations, the interaction involves guanine-N7/O6, adenine-N7, and uracil-O2 reactive sites, as well as the phosphate and the ribose backbone. In addition, the participation of the primary amino group of the polycations in polyamine binding and the presence of hydrophobic contacts were demonstrated. Capillary electrophoresis study reveals that longchain polyamines (spermine and spermidine) bind more strongly than a small one (putrescine). This finding is in agreement with the NMR studies, which suggested that secondary amino groups bind more strongly than primary amino groups (Frydman et al. 1990, 1992, 1996, 1999; Fernandez et al. 1994). The high binding affinity of biogenic polyamines to tRNA molecule was in

TABLE 3. Ribonucleotides in the vicinity of putrescine, spermidine, and spermine in tRNA (PDB ID: 6TNA) and the free binding energies of the docked complexes

\begin{tabular}{lcc}
\hline Complex & Ribonucleotides involved in interactions & $\Delta G_{\text {binding }}$ \\
\hline Putrescine-tRNA & A9, A23, G24, A25, G26, G43, A44, G45 & -4.04 \\
Spermidine-tRNA & A23, G24, A25, G26, C27, G43, A44, G45 & -3.81 \\
Spermine-tRNA & A23, G24, A25, G26, C27, G42, G43, A44, G45 & -3.57 \\
\hline
\end{tabular}


the order spermine $>$ spermidine $>$ putrescine, which correlates with their charged amino group content. Cobalt(III)hexamine contains high- and low-affinity sites in tRNA, which have been attributed to the interactions with guanine-N7 sites and the phosphate backbone. This mechanism of tRNA binding could explain the condensation phenomenon observed at high $\mathrm{Co}$ (III) content, as reported in the Co(III)-DNA complexes (Ahmed Ouameur and Tajmir-Riahi 2004).

In order to perform a meaningful comparison with our infrared spectroscopic results, we further studied the interactions between putrescine, spermidine, and spermine molecules and tRNA using a molecular docking approach. The results showed several models of interactions between putrescine, spermidine, spermine, and tRNA (Fig. 5; Table 3). The X-ray study (Quigley et al. 1978) showed two binding sites for spermine-one in the major groove of the double helical region in the anticodon stem and another in the deep pocket formed by bending of the D-stem nucleosides toward those of the variable loop. H-NMR analysis showed that only one spermine molecule binds tRNA (Frydman et al. 1996); the binding site was located in the T $\psi \mathrm{C}$-loop. Using a docking approach, it would appear that spermine binds in the major groove. The docking of spermine in the T $\psi \mathrm{C}$-loop showed a negative free binding energy $(-3.19 \mathrm{kcal} / \mathrm{mol}$, docking not shown) but still higher than the value obtained from the docking in the major groove $(-3.57 \mathrm{kcal} / \mathrm{mol})$. This would indicate that both the T $\psi \mathrm{C}$-loop and the major groove are potential binding sites for polyamines, with the major groove being the preferred one. Other findings suggest that the major factor determining the binding of the spermine analogs to AcPhe-tRNA is the polyamine part of analogs, not the photoactivated substrate (Amarantos and Kalpaxis 2000). A recent study has suggested that polyamines are located at the bulged-out region of double-stranded RNA and affect RNA function (Higashi et al. 2008). Our infrared spectroscopic analysis of the interaction between spermine and tRNA revealed that the preferential binding sites at low spermine concentration are guanine $(\mathrm{C}=\mathrm{O} 6 / \mathrm{N} 7)$ and uracil $(\mathrm{C}=\mathrm{O} 2)$. By increasing the concentration of spermine, new sites of interaction appeared [adenine $(\mathrm{C}=\mathrm{N} 3), \mathrm{PO}_{2}, \mathrm{OH} 2{ }^{\prime}$-ribose], and the presence of hydrophobic contacts between spermine and methyl groups of tRNA are evident.

This study highlights the mechanism of interaction between biogenic polyamines and tRNA and might help to design polyamine analogs with a growth inhibitory effect. Therefore, studying the interaction between polyamine analogs and macromolecules (protein, DNA, and tRNA) is a current and future research priority.

\section{MATERIALS AND METHODS}

\section{Materials}

Biogenic polyamines (spermine, spermidine, and putrescine) and cobalt(III)-hexamine were purchased from Sigma Chemical Com- pany. tRNA from Baker's yeast was purchased from Sigma Chemical Co. and used as supplied. The absorbance at 260 and $280 \mathrm{~nm}$ was used, in order to check the protein content of tRNA solution. The $A_{260} / A_{280}$ ratio was 2.2 , showing that the tRNA was sufficiently free from protein (Marmur 1961). Other chemicals were of reagent grade and used without further purification.

\section{Preparation of stock solutions}

Stock tRNA solution was prepared by dissolving $10 \mathrm{mg}$ of tRNA in $20 \mathrm{mM}$ Tris- $\mathrm{HCl}$ buffer ( $\mathrm{pH}$ 7.4). The final concentration of the stock tRNA solution was determined spectrophotometrically at $260 \mathrm{~nm}$, using a molar extinction coefficient of $\epsilon_{260}=9250 \mathrm{~cm}^{-1}$ $\mathrm{M}^{-1}$ (expressed as molarity of phosphate groups) (Cantor et al. 1970). The UV absorbance at $260 \mathrm{~nm}$ of a diluted solution $(1 / 250)$ of tRNA used in our experiments was measured to be 0.925 (the path length was $1 \mathrm{~cm}$ ), and the final concentration of the stock tRNA solution was calculated to be $25 \mathrm{mM}$ in tRNA phosphate. The appropriate amount of polyamines $(0.3-25 \mathrm{mM})$ was prepared in distilled water and added dropwise to tRNA solution, in order to attain the desired polyamine/tRNA(P) molar ratios $(r)$ of $1 / 80,1 / 40,1 / 20,1 / 10,1 / 4,1 / 2$, and 1 at a final tRNA concentration of $12.5 \mathrm{mM}(5 \mathrm{mg} / \mathrm{mL})$ for infrared measurements. For capillary electrophoresis, the polyamine/tRNA(P) ratios were $1 / 800,1 / 400,1 / 200,1 / 100,1 / 50,1 / 25,1 / 12.5$, and $1 / 6.25$ with a final tRNA concentration of $1.25 \mathrm{mM}$. The $\mathrm{pH}$ of the solutions was adjusted to $7.0 \pm 0.2$ using $\mathrm{NaOH}$ solution.

\section{FTIR spectra}

Infrared spectra were recorded on a FTIR spectrometer (Impact 420 model), equipped with a DTGS (deuterated triglycine sulfate) detector and a $\mathrm{KBr}$ beam splitter, using $\mathrm{AgBr}$ windows. Spectra were collected after $2 \mathrm{~h}$ of incubation of polyamine with the polynucleotide solution and measured in triplicate (three individual samples with the same polynucleotide and polyamine concentrations). Interferograms were accumulated over the spectral range $4000-600 \mathrm{~cm}^{-1}$ with a nominal resolution of $2 \mathrm{~cm}^{-1}$ and a minimum of 100 scans. The difference spectra [(tRNA solution + polyamine $)-($ tRNA solution $)$ ] were obtained using a sharp tRNA band at $966 \mathrm{~cm}^{-1}$ as the internal reference. This band is due to ribose $\mathrm{C}-\mathrm{C}$ stretching vibration, exhibits no spectral changes (shifting or intensity variation) upon polyamine-tRNA complexation, and is canceled out on spectral subtraction (Ahmed Ouameur et al. 2004a; Marty et al. 2004a).

The plots of the relative intensity $(R)$ of several tRNA vibrations related to $\mathrm{A}-\mathrm{U}, \mathrm{G}-\mathrm{C}$ base pairs and the $\mathrm{PO}_{2}$ stretching modes versus the polyamine concentrations were obtained after peak normalization using:

$$
R_{i}=\frac{I_{i}}{I_{966}}
$$

where $I_{i}$ is the intensity of the absorption band for pure tRNA and tRNA in the complex with $i$ concentration of polyamine, and $I_{966}$ is the intensity of the $966 \mathrm{~cm}^{-1}$ peak (internal reference) (Ahmed Ouameur and Tajmir-Riahi 2004).

\section{Capillary electrophoresis}

A PACE System MDQ (Beckman) with photodiode array detector was used to study polyamine-tRNA interaction. An uncoated 
fused silica capillary of $75 \mu \mathrm{m}$ i.d. (total length of $57 \mathrm{~cm}$ ) and effective length of $50 \mathrm{~cm}$ (to the detector) was used. The capillary was conditioned each day by rinsing with $1 \mathrm{~N}$ sodium hydroxide for $30 \mathrm{~min}$, followed by a $15-\mathrm{min}$ wash with $0.1 \mathrm{~N}$ sodium hydroxide. Then it was rinsed with running buffer for $30 \mathrm{~min}$ at high pressure ( $50 \mathrm{psi}$ ), followed by a baseline run for $20 \mathrm{~min}$ at the voltage to be used for the experiments $(25 \mathrm{kV})$. Between runs, the capillary was rinsed with $1 \mathrm{~N} \mathrm{NaOH}$ for $2 \mathrm{~min}$, followed by rinsing with running buffer for $3 \mathrm{~min}$ at high pressure. The capillary was flushed with distilled deionized water for $30 \mathrm{~min}$ at the end for each day and filled with deionized water overnight. Samples were injected using a voltage injection at $10 \mathrm{kV}$ for $5 \mathrm{sec}$. Electrophoresis was carried out at a voltage of $25 \mathrm{kV}$ for 10 min using normal polarity. All runs were carried out at $25^{\circ} \mathrm{C}$. The capillary inlet and outlet vials were replenished after every five runs. The polyamine binding experiments were performed in a sample buffer containing $20 \mathrm{mM}$ Tris- $\mathrm{HCl}(\mathrm{pH} 7.0 \pm 0.2)$, using a constant concentration of tRNA $(1.25 \mathrm{mM})$ and variable concentrations of polyamines. The stock solutions of polyamines $(2.5 \mathrm{mM})$ and tRNA $(2.5 \mathrm{mM})$ were prepared in the sample buffer. The solutions were mixed to attain polyamine/tRNA(P) molar ratios of $1 / 800$ to $1 / 6.25$, in the presence of $1.25 \mathrm{mM}$ tRNA. Each sample was allowed to equilibrate for 30 min and tested with two separate runs for the same stock solution. The electropherograms were monitored at $260 \mathrm{~nm}$ and were collected and analyzed with the Beckman P/ACE Windows controller software.

\section{Data analysis}

Affinity capillary electrophoresis (ACE) was used to detect a shift in mobility when polyamine binds to tRNA. The binding constants for the polyamine-tRNA complexes can be determined by Scatchard analysis, using mobility shift of tRNA complexes (Klotz 1982; Guszcynski and Copeland 1998). The extent of saturation $\left(R_{\mathrm{f}}\right)$ of the tRNA was determined from the change of the migration time of tRNA, in the presence of various concentrations of polyamine by the following equation:

$$
R_{\mathrm{f}}=\frac{\Delta m}{\Delta m_{\mathrm{s}}}
$$

where $\Delta m$ is the difference in migration time between pure tRNA and its complexes at different polyamine concentrations, while $\Delta m_{\mathrm{s}}$ corresponds to the difference in migration time between pure tRNA and tRNA-saturated complex.

The binding constant $K_{\mathrm{b}}$, given by

$$
K_{\mathrm{b}}=\frac{[\text { polyamine }- \text { tRNA adduct }]}{[\text { tRNA }][\text { polyamine }]},
$$

was determined by fitting the experimental values of $R_{\mathrm{f}}$ and polyamine concentration to the equation:

$$
R_{\mathrm{f}}=\frac{K_{\mathrm{b}}[\text { polyamine }]}{1+K_{\mathrm{b}}[\text { polyamine }]} .
$$

Rearrangement of this gives a convenient form for Scatchard analysis:

$$
\frac{R_{\mathrm{f}}}{\text { [polyamine }]}=K_{\mathrm{b}}-K_{\mathrm{b}} R_{\mathrm{f}}
$$

Capillary electrophoresis has become a useful technique for measuring binding constants (Guijt-van Duijn et al. 2000). Using the affinity capillary electrophoresis (ACE) method, many ligandpolynucleotide complexes have been successfully identified in our laboratory (Arakawa et al. 2000, 2001; Ahmed Ouameur and Tajmir-Riahi 2004; Ahmed Ouameur et al. 2004a,b; Marty et al. 2004b).

The cooperativity of the binding can be analyzed using a Hill plot. Assuming one binding site for polyamine (Equation 5), the equation shown below (Hill equation) can be established:

$$
\log \frac{R_{\mathrm{f}}}{1-R_{\mathrm{f}}}=\mathrm{n} \log [\text { polyamine }]+\log K_{\mathrm{d}},
$$

where $n$ (Hill coefficient) measures the degree of cooperativity and $K_{\mathrm{d}}$ is the dissociation constant. The linear plot of $\log \left\{R_{\mathrm{f}} /\left(R_{\mathrm{f}}-1\right)\right\}$ versus $\log$ [polyamine] has a slope of $n$ and an intercept on the $\log$ [polyamine] axis of $\log K_{\mathrm{d}} / \mathrm{n}$. The quantity $n$ increases with the degree of cooperativity of a reaction and thereby provides a convenient and simplistic characterization of a ligand-binding reaction (Jack 1995).

\section{Molecular modeling and docking}

The docking studies were performed with ArgusLab 4.0.1 software (Planaria Software LLC; http://www.arguslab.com). tRNA structure was obtained from the PDB (ID: 6TNA) (Sussman et al. 1978), and the polyamine three-dimensional structures were generated from PM3 semi-empirical calculations using Chem3D Ultra 6.0. According to X-ray (Quigley et al. 1978) and ${ }^{1} \mathrm{H}-\mathrm{NMR}$ (Frydman et al. 1996) data, three possible binding sites (major groove, variable loop, and T $\psi \mathrm{C}$-loop) were searched. The docking runs were performed on the ArgusDock docking engine using high precision with a maximum of 150 candidate poses. The conformations were ranked using the Ascore scoring function, which estimates the free binding energy. Upon docking of polyamines to tRNA, the current configurations were optimized using a steepest decent algorithm until convergence, within 40 iterations, and nucleobase residues within a distance of $3.5 \AA$ relative to polyamines were involved in the complexation.

\section{ACKNOWLEDGMENTS}

We highly appreciate the financial support of the Natural Sciences and Engineering Research Council of Canada (NSERC).

Received November 10, 2009; accepted July 15, 2010.

\section{REFERENCES}

Agrawal RK, Penczek P, Grassucci RA, Burkhardt N, Nierhaus KH, Frank J. 1999. Effect of buffer conditions on the position of tRNA on the $70 \mathrm{~S}$ ribosome as visualized by cryoelectron microscopy. J Biol Chem 274: 8723-8729.

Ahmed Ouameur A, Tajmir-Riahi HA. 2004. Structural analysis of DNA interactions with biogenic polyamines and cobalt(III)hexamine studied by Fourier transform infrared and capillary electrophoresis. J Biol Chem 279: 42041-42054.

Ahmed Ouameur A, Malonga H, Neault J-F, Diamantoglou S, TajmirRiahi HA. 2004a. Taxol interaction with DNA and RNA—stability and structural features. Can J Chem 82: 1112-1118. 
Ahmed Ouameur A, Marty R, Neault J-F, Tajmir-Riahi HA. 2004b. AZT binds RNA at multiple sites. DNA Cell Biol 23: 783-788.

Amarantos I, Kalpaxis DL. 2000. Photoaffinity polyamines: Interactions with AcPhe-tRNA free in solution or bound at the P-site of Escherichia coli ribosomes. Nucleic Acids Res 28: 3733-3742.

Arakawa H, Ahmad R, Naoui M, Tajmir-Riahi HA. 2000. A comparative study of calf-thymus DNA binding to $\mathrm{Cr}$ (III) and $\mathrm{Cr}(\mathrm{VI})$ ions: Evidence for the guanine N-7 chromium-phosphate chelate formation. J Biol Chem 275: 10150-10153.

Arakawa H, Neault J-F, Tajmir-Riahi HA. 2001. Silver(I) complexes with DNA and RNA studied by Fourier transform infrared spectroscopy and capillary electrophoresis. Biophys J 81: 1580-1587.

Bacchi CJ, Weiss LM, Lane S, Frydman B, Valasinas A, Reddy V, Sun JS, Marton LJ, Khan IA, Moretto M, et al. 2002. Novel synthetic polyamines are effective in the treatment of experimental microsporidiosis, an opportunistic AIDS-associated infection. Antimicrob Agents Chemother 46: 55-61.

Bachrach U. 2005. Naturally occurring polyamines: Interaction with macromolecules. Curr Protein Pept Sci 6: 559-566.

Bibillo A, Figlerowicz M, Kierzek R. 1999. The non-enzymatic hydrolysis of oligoribonucleotides. VI. The role of biogenic polyamines. Nucleic Acids Res 27: 3931-3937.

Bolton PH, Kearns DR. 1978. Hydrogen bonding interactions of polyamines with the 2'OH of RNA. Nucleic Acids Res 5: 1315-1324.

Cantor CR, Warshaw MM, Shapiro H. 1970. Oligonucleotide interactions. III. Circular dichroism studies of the conformation of deoxyoligonucleotides. Biopolymers 9: 1059-1077.

Childs AC, Mehta DJ, Gerner EW. 2003. Polyamine-dependent gene expression. Cell Mol Life Sci 60: 1394-1406.

Cohen SS. 1998. A guide to the polyamines. Oxford University Press, New York.

Dhaouadi Z, Ghomi M, Austin JC, Girling RB, Hester RE, Mojzes P, Chinsky L, Turpin PY, Coulombeau C, Jobic H, et al. 1993. Vibrational motions of bases of nucleic acids as revealed by neutron inelastic scattering and resonance Raman spectroscopy: 1. Adenine and its deuterated species. J Phys Chem 97: 1074-1084

Fernandez CO, Frydman B, Samejima K. 1994. Interactions between polyamine analogs with antiproliferative effects and tRNA: A ${ }^{15} \mathrm{~N}$ NMR analysis. Cell Mol Biol 40: 933-944.

Fernández CO, Buldain G, Samejima K. 2000. Probing the interaction between $N^{1}, N^{4}$-dibenzylputrescine and tRNA through ${ }^{15} \mathrm{~N}$ NMR: Biological implications. Biochim Biophys Acta 1476: 324-330.

Feuerstein BG, Williams LD, Basu HS, Marton LJ. 1991. Implications and concepts of polyamine-nucleic acid interactions. J Cell Biochem 46: 37-47.

Fichera M, Gregoli L, Musumarra G. 2000. 2,6-Di(heteroarylvinyl)pyridines as new potential antitumor agents. J Phys Org Chem 13: 344-346.

Frydman B, Valasinas A. 1999. Polyamine-based chemotherapy of cancer. Exp Opin Ther Patents 9: 1055-1068.

Frydman B, de los Santos C, Frydman RB. 1990. A ${ }^{13}$ C NMR study of $\left[5,8-{ }^{13} \mathrm{C}_{2}\right]$ spermidine binding to tRNA and to Escherichia coli macromolecules. J Biol Chem 265: 20874-20878.

Frydman L, Rossomando PC, Frydman V, Fernandez CO, Frydman B, Samejima K. 1992. Interactions between natural polyamines and tRNA: An ${ }^{15}$ N-NMR analysis. Proc Natl Acad Sci 89: 9186-9190.

Frydman B, Westler WM, Samejima K. 1996. Spermine binds in solution to the T $\psi \mathrm{C}$ loop of tRNA ${ }^{\text {Phe }}$ : Evidence from a $750 \mathrm{MHz}$ ${ }^{1}$ H-NMR analysis. J Org Chem 61: 2588-2589.

Frydman B, Westler WM, Valasinas A, Kramer DL, Porter CW. 1999. Regioselective binding of spermine, $N^{1}, N^{12}$-bismethylspermine, and $N^{1}, N^{12}$-bisethylspermine to tRNA $^{\text {Phe }}$ as revealed by 750 $\mathrm{MHz}{ }^{1} \mathrm{H}-\mathrm{NMR}$ and its possible correlation with cell cycling and cytotoxicity. J Braz Chem Soc 10: 334-340.

Frydman B, Porter CW, Maxuitenko Y, Sarkar A, Bhattacharya S, Valasinas A, Reddy VK, Kisiel N, Marton LJ, Basu HS. 2003. A novel polyamine analog (SL-11093) inhibits growth of human prostate tumor xenografts in nude mice. Cancer Chemother Pharmacol 51: 488-492.
Gosule LC, Schellman JA. 1976. Compact form of DNA induced by spermidine. Nature 259: 333-335.

Guijt-van Duijn RM, Frank J, van Dedem GWK, Baltussen E. 2000. Recnt advances in affinity capillary electrophoresis. Electrophoresis 21: 3905-3918.

Günzler H, Gremlich H-U. 2002. IR spectroscopy, An introduction. Wiley-vch, Germany.

Guszcynski T, Copeland TD. 1998. A binding shift assay for the zincbound and zinc-free HIV-1 nucleocapsid protein by capillary electrophoresis. Anal Biochem 260: 212-217.

Higashi K, Terui Y, Suganami A, Tamura Y, Nishimura K, Kashiwagi K, Igarashi K. 2008. Selective structural change by spermidine in the bulged-out region of double-stranded RNA and its effect on RNA function. J Biol Chem 283: 32989-32994.

Igarashi K, Kashiwagi K. 2000. Polyamines: Mysterious modulators of cellular functions. Biochem Biophys Res Commun 271: 559-564.

Igarashi K, Kashiwagi K. 2006. Polyamine modulon in Escherichia coli: Genes involved in the stimulation of cell growth by polyamines. J Biochem 139: 11-16.

Jack RC. 1995. Basic biochemical laboratory procedures and computing. Oxford University Press, New York.

Kieft JS, Tinoco I Jr. 1997. Solution structure of a metal-binding site in the major groove of RNA complexed with cobalt(III)hexamine. Structure 5: 713-721.

Klotz MI. 1982. Numbers of receptor sites from Scatchard graphs: Facts and fantasies. Science 217: 1247-1249.

Kouvela EC, Petropoloulos AD, Kalpaxis DL. 2006. Unraveling new features of clindamycin interaction with functional ribosomes and dependence of the drug potency on polyamines. J Biol Chem 281: 23103-23110.

Li Y, Eiseman JL, Sentz DL, Rogers FA, Pan SS, Hu L-T, Egorin MJ, Callery PS. 1996. Synthesis and antitumor evaluation of a highly potent cytotoxic DNA cross-linking polyamine analogue, 1,12diaziridinyl-4,9-diazadodecane. J Med Chem 39: 339-341.

Marmur J. 1961. A procedure for isolation of deoxyribonucleic acid from micro-organisms. J Mol Biol 3: 208-218.

Marton LJ, Pegg AE. 1995. Polyamines as targets for therapeutic intervention. Annu Rev Pharmacol Toxicol 35: 55-91.

Marty R, Ouameur AA, Neault JF, Tajmir-Riahi HA. 2004a. RNA adducts with chlorophyll and chlorophyllin: Stability and structural features. J Biomol Struct Dyn 22: 45-50.

Marty R, Ouameur AA, Neault J-F, Tajmir-Riahi HA. 2004b. AZTDNA interaction. DNA Cell Biol 23: 135-140.

Nakamoto K. 1997. Infrared and Raman spectra of inorganic and coordination compounds (Part B: applications in coordination, organometallic, and bioinorganic chemistry). Wiley, New York.

Pavia DL, Lampman GM, Kriz GS. 1979. Introduction to spectroscopy: A guide for students of organic chemistry. Saunders, Toronto, Canada.

Quigley GJ, Teeter MM, Rich A. 1978. Structural analysis of spermine and magnesium ion binding to yeast phenylalanine transfer RNA. Proc Natl Acad Sci 75: 64-68.

Rüdisser S, Tinoco I Jr. 1999. Solution structure of cobalt(III)hexammine complexed to the GAAA tetraloop, and metal-ion binding to G.A mismatches. J Mol Biol 295: 1211-1223.

Shi H, Moore PB. 2000. The crystal structure of yeast phenylalanine tRNA at $1.93 \AA$ resolution. A classic structure revisited. RNA 6: 1091-1105.

Shimogori T, Kashiwagi K, Igarashi K. 1996. Spermidine regulation of protein synthesis at the level of initiation complex formation of Met-tRNA, mRNA and ribosomes. Biochem Biophys Res Commun 223: $544-548$.

Sussman JL, Holbrook SR, Warrant RW, Church GM, Kim S-H. 1978. Crystal structure of yeast phenylalanine transfer RNA: I. Crystallographic refinement. J Mol Biol 123: 607-630.

Tabor H, Tabor CW. 1984. Polyamines. Annu Rev Biochem 53: 749790.

Taillandier E, Liquier J. 1992. Infrared spectroscopy of DNA. Methods Enzymol 211: 307-335. 
Taillandier E, Liquier J, Taboury JA, Ghomi M. 1984a. Structural transitions in DNA (A, B, Z) studied by IR spectroscopy. In Spectroscopy of biological molecules (ed. C Sandorfy, T Theophanides), pp.171-189. Reidel Dordrecht, Amsterdam.

Taillandier E, Taboury JA, Adam S, Liquier J. 1984b. Left-handed helical structure of poly $[\mathrm{d}(\mathrm{A}-\mathrm{C}) \cdot \operatorname{poly}[\mathrm{d}(\mathrm{G}-\mathrm{T})]$ studied by infrared spectroscopy. Biochemistry 23: 5703-5706.

Taillandier E, Liquier J, Taboury JA. 1985. Infrared spectral studies of DNA conformations. Adv Infrared Raman Spectrosc 12: 65-113.

Theophanides T, Tajmir-Riahi HA. 1985. Flexibility of DNA and RNA upon binding to different metal cations. An investigation of the $B$ to $\mathrm{A}$ to $\mathrm{Z}$ conformational transition by Fourier transform infrared spectroscopy. J Biomol Struct Dyn 2: 995-1004.

Thomas T, Thomas TJ. 2001. Polyamines in cell growth and cell death: Molecular mechanisms and therapeutic applications. Cell Mol Life Sci 58: 244-258.
Thomas T, Thomas TJ. 2003. Polyamine metabolism and cancer. J Cell Mol Med 7: 113-126.

Thomas T, Balabhadrapathruni S, Gallo MA, Thomas TJ. 2002. Development of polyamine analogs as cancer therapeutic agents. Oncol Res 13: 123-135.

Tsuboi M. 1970. Application of infrared spectroscopy to structure studies of nucleic acids. Appl Spectrosc Rev 3: 45-90.

Watanabe S, Kusama-Eguchi K, Kobayashi H, Igarashi K. 1991. Estimation of polyamine binding to macromolecules and ATP in bovine lymphocytes and rat liver. J Biol Chem 266: 2080320809.

Yoshida M, Meksuriyen D, Kashiwagi K, Kawai G, Igarashi K. 1999. Polyamine stimulation of the synthesis of oligopeptide-binding protein (OppA). Involvement of a structural change of the ShineDalgarno sequence and the initiation codon AUG in oppa mRNA. J Biol Chem 274: 22723-22728. 

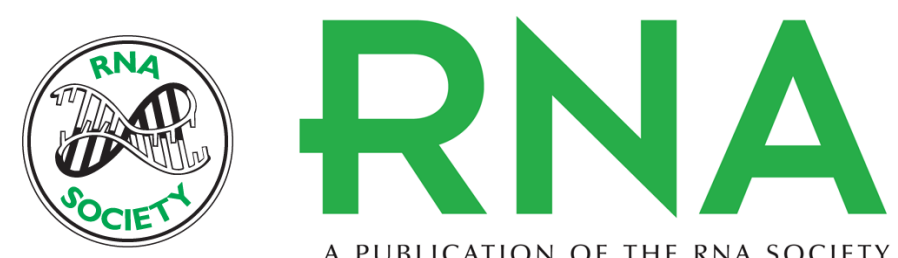

A PUBLICATION OF THE RNA SOCIETY

\section{Probing tRNA interaction with biogenic polyamines}

Amin Ahmed Ouameur, Philippe Bourassa and Heidar-Ali Tajmir-Riahi

RNA 2010 16: 1968-1979 originally published online August 20, 2010

Access the most recent version at doi:10.1261/rna.1994310

\section{References This article cites 54 articles, 13 of which can be accessed free at:} http://rnajournal.cshlp.org/content/16/10/1968.full.html\#ref-list-1

\section{License}

Email Alerting Receive free email alerts when new articles cite this article - sign up in the box at the Service top right corner of the article or click here. 